\title{
An Eddy Current System for High Speed Inspection of M-16 Cartridge Cases
}

by

R. A. Dilbeck

T. J. Davis

Prepared for the

U.S. Department of Energy

under Contract EY-76-C-06-1830 


\section{DISCLAIMER}

This report was prepared as an account of work sponsored by an agency of the United States Government. Neither the United States Government nor any agency Thereof, nor any of their employees, makes any warranty, express or implied, or assumes any legal liability or responsibility for the accuracy, completeness, or usefulness of any information, apparatus, product, or process disclosed, or represents that its use would not infringe privately owned rights. Reference herein to any specific commercial product, process, or service by trade name, trademark, manufacturer, or otherwise does not necessarily constitute or imply its endorsement, recommendation, or favoring by the United States Government or any agency thereof. The views and opinions of authors expressed herein do not necessarily state or reflect those of the United States Government or any agency thereof. 


\section{DISCLAIMER}

Portions of this document may be illegible in electronic image products. Images are produced from the best available original document. 
AN EDDY CURRENT SYSTEM FOR HIGH SPEED

INSPECTION OF M-16 CARTRIDGE CASES

by

R.A. Dilbeck

T.J. Davis

Battelle-Northwest

Richland, Washington

This report was preparicE sponsored by the United Siates Government. Neither the

United States nor the United States Deperther

Energy, nor any of their emplos Department of

contesctors, subcons their employoes, noz any of dizet

any wars, sybons

liability or rexpess of implied, or assumes any legal

or uefulness of any infor the accuracy, completeness

process disclosed, or intion, apparatus, product or

infress disclosed, or represents that its use would not

March 1978

Prepared for the U.S. Army, Picatinny Arsenal under research contract \#300A00792, under related servires agreement, U.S. Department of Energy Contract EY-76-C-06-1830. 


\author{
AN EDDY CURRENT SYSTEM FOR HIGH SPEED \\ INSPECTION OF M-16 CARTRIDGE CASES \\ R. A. Dilbeck and T. J. Davis \\ Battelle-Northwest \\ Richland, Washington \\ (BNWL-SA-6472)
}

\begin{abstract}
This paper describes an eddy current system developed to detect cracks, splits, and folds in $5.56 \mathrm{~mm}$ cartridge cases at a rate of 1200 cases/minute. The system inspects each cartridge case around its entire circumference, and has an operating frequency of $100 \mathrm{kHz}$ which minimizes sensitivity to wall thickness variations. Also discussed in this paper is the use of this instrument to monitor cartridge case wall thickness by reducing the operating frequency. At a frequency of $25 \mathrm{kHz}$, wall thickness can be measured with an accuracy of $0.013 \mathrm{~mm}(0.0005 \mathrm{in.})$. Maximum, minimum, and average wall thickness are simultaneously recorded for each case about its circumference at four different locations on the case.

Also described are some rather unique features of the electronitic instrument. "These include an oblong search coil which is contoured to cartridge case motion, a temperature stabilization method based on constant current excitation of send-receive coils, and a rapid automatic nulling technique employing digital methods. Additionally, a method for using a Q-multiplier as either an oscillator or a bandpass filter is described. This method facilitates the use of a bandpass filter that is precisely matched to the eddy current signal generator so that no output phase error occurs during minute drifts in test frequency.
\end{abstract}


AN EDDY CURRENT SYSTEM FOR HIGH SPEED

INSPECTION OF M-16 CARTRIDGE CASES $(a)$

R. A. Dilbeck and T. J. Davis

Battelle-Northwest

Richland, Washington

\section{INTRODUCTION}

The eddy current system described in this paper was developed to detect cracks, splits, folds and case thickness in $5.56 \mathrm{~mm}$ cartridge cases used by the military for small arms ammunition. When installed on the production line, the system is capable of inspecting the cases at a throughput rate of 1200 cases/minute. The eddy current system is one of four instruments which comprise a cartridge case measurement/eject system that has been developed for the U.S. Army for production line use. The other three instruments in the system are an optical vent hole monitor, an optical surface flaw monitor, and an optical profile monitor which measures five dimensions of the cases. The composite system serves to: 1) eject faulty cases from the production stream and 2) provide early warning of out-of-control process conditions and identify the responsible parallel manufacturing line.

\section{SUMMARY}

The eddy current system can reject cases with flaws as small as $32 \mathrm{~mm}$ ( $0.125 \mathrm{in.}$ ) in length, $0.05 \mathrm{~mm}(0.002 \mathrm{in.})$ in width, and half the wall thickness in depth. Wall thickness of the cases, which ranges from $0.6 \mathrm{~mm}$ $(0.024 \mathrm{in.})$ at the head to $0.3 \mathrm{~mm}(0.012 \mathrm{in.})$ at the mouth, can be measured with an accuracy of $0.013 \mathrm{~mm}(0.0005 \mathrm{in.}$.).

(a) This work was sponsored by the U.S. Army, Picatinny Arsenal under research contract \#300A00792. 


\section{INSPECTION REQUIREMENTS}

A variety of flaws can be developed during the case forming process depending on the quality of the brass material and forming tools. Typical flaws and their commonly occurring locations are indicated in Figure 1. Eddy current inspection is performed in zones two and four as shown in the figure, and is primarily used to detect subsurface cracks which are not detected by optical surface monitoring. Additionally, the eddy current test serves as a backup for detection of other flaws which may be missed by the optical monitoring due to orientation or non-abrupt surface variations. These flaws include splits (through-the-wall cracks), perforations (holes punched by pointed objects), and geometrical anomalies known as folds, wrinkles and buckles. Also, a portion of the mouth can be melted away during an out-of-control annealing process.

All of these defects are considered critical because they can affect the gas seal, allow the powder to draw moisture, and/or allow powder to leak out. Any of these conditions can cause misfire or jamming of a weapon.

\section{INSPECTION SYSTEM}

\section{FLAW DETECTION}

During the inspection process the cartridge cases are transported on rotary spindles past an eddy current flaw station. The spindles hold the case at the head and the mouth. The cases are spun at $3600 \mathrm{rpm}$ as they pass the inspection head so that elongated inspection coils can inspect the complete circumference of the case. A photograph of the eddy current probe mounted on a cartridge transport system is shown in Figure 2. Two elongated coils, imbedded in the eddy current head, are contoured to conform to the circular case transiation path. One inspects the head of the case and the other inspects the case mouth as shown in Figure 3. 
Eddy current inspection can detect flaws having a length as small as $3.2 \mathrm{~mm}(0.125 \mathrm{in.})$ and a width as small as $0.05 \mathrm{~mm}(0.002 \mathrm{in.})$. Furthermore, flaws need not completely penetrate the cartridge case in order to be detected. In the head region, the flaws generally originate on the inside of the case. If the flaw extends to within approximately $0.3 \mathrm{~mm}(0.012 \mathrm{in}$. of the surface (half the nominal thickness), the flaw will be detected at the current reject settings. In the mouth region, wall thickness is nomi-: nally $0.3 \mathrm{~mm}$ ( $0.012 \mathrm{in.})$ and an ID flaw of half this depth will be detected. The flaws can be detected directly in front of the coil or up to approximately $5 \mathrm{~mm}(0.2 \mathrm{in.})$ above or below the edge of the coil.

The complex plane eddy current response as a good case is translated past a coil as shown in Figure 4a. The data is rotated until case motion (1iftoff) affects only the horizontal channel. Deflection in the vertical channel is used as a measure of flaw size or case thickness, depending upon the test frequency employed. A reject alarm is placed on the vertical channel to indicate an accept/reject condition for the case being measured. The instrument generates one bit of information (accept or reject) for each of the two coils and one case-present bit. These three binary bits are transmitted to a computer on a serial data link. The computer enters the data into a running inventory and displays data from all four inspection methods on a video display. The computer provides early warning of out-of-control process conditions and identifies which parallel case manufacturing line is producing faulty cases.

\section{THICKNESS MEASUREMENT}

The eddy current flaw test operates at a frequency of $100 \mathrm{kHz}$ to minimize the effects of wall thickness variations. Although a modified version of the instrument, operating at $25 \mathrm{kHz}$, was used to demonstrate case wall thickness measurement, this measurement is not currently implemented on the production line. A typical response for case thickness is shown in Figure 4-b. Four coils were used for thickness measurement, as shown in fiqure 5. In the demonstration, variations in wall thickness were measured to an accuracy of $0.013 \mathrm{~mm}(0.0005 \mathrm{in})$. The maximum, minimum and 
average wall thicknesses were measured using an integrating analog to digital converter. The digital data were sent to the computer where a running mean and standard deviation of the measurements were kept and displayed on request.

\section{ELECTRONIC INSTRUMENT}

The instrument utilizes conventional eddy current technology coupled with some specialized features which make it especially suited for inspection of cartridge cases. These features include a contoured oblong search coil, constant current coil excitation, digital automatic nulling, and a circuit that operates either as an oscillator or a bandpass filter for achieving output stability.

A block diagram of one channel of the instrument is shown in Figure 6 . An oscillator and a coil driver excite dual drive coils with constant amplitude current. Sense and reference receive coil signals are brought out for amplification by a differential amplifier. The amplified signal is then summed with an output from the autonull circuit which is made equal and $180^{\circ}$ out of phase. The resulting nulled signal is applied to a bandpass filter and then to a pair of phase-sensitive amplitude detectors. The outputs of these detectors are proportional to the Fourier amplitude coefficients of eddy currents flowing in the cartridge case. The outputs of the phasesensitive detectors are rotated until liftoff is contained in one output channel. The other channel is then used as a measure of thickness or defects in the cartridge case.

The elongated sense coils are contoured to the case path as shown in Figure 3. This results in minimized liftoff variations and constant fill 1 factor while the case is in the inspection field. The case is rotated as it passes the coils so that its full circumference is inspected. A sketch of the coil form is shown in Figure 7. The sense coil pair is wound on a flexible bobbin made of Lexan TM, which is a polycarbonate-based plastic. The bobbin is then flexed and cemented to the contoured front of the reference coil bobbin. 
Temperature stability of the test is provided by driver-pickup coil arrangements in which the drivers are excited by constant amplitude current, and by the use of reference coils for ambient effect compensation. The probe contains two pairs of coils, a sense coil pair and a reference coil pair; each pair consists of a driver and a pickup coil. The electrical arrangement of the coils is shown in Figure 8. The constant current excitation of driver coils insures that the excitation amp-turns are maintained at a constant value. As a result, the pickup coil voltage produced by eddy currents in the specimen will be completely independent of temperature-induced coil resistance changes. The reference coil pair compensates for other temperaturerelated effects such as conductivity variations in the metallic probe housing and thermal expansion of the coils.

The constant current generator is shown in Figure 9. In the generator a unity gain voltage driver excites a resonant LC circuit which contains the driver coils. If the inductor $L$ has a reactance 50 to 100 times greater than that of the driver coils, the driver coil current will be constant and essentially independent of driver coil impedance. The capacitor $C$ resonates the combined inductances at the test frequency, drawing a leading current approximately equal to the coil lagging current. The result is that the output current of the voltage driver need only be a small fraction of the desired coil current. This substantially reduces the requirements of the voltage driver, allowing use of a wide variety of devices. The inductor $L$ must be a stable high $Q$ device with minimal temperature sensitivity in order to maintain the current at a constant level.

Bandpass filtering of the amplified test signal is performed with excellent stability by a circuit whose tuning network is identical to that used for the oscillator. Since the two tuning networks are maintained in the same environment, they track each other and essentially no phase error or drift is encountered for slight changes in oscillator frequency or filter center frequency. The circuits are shown in Figure 10. The oscillator is a conventional Wein bridge unit with automatic gain control (AGC). If $R 1=R 2$ and $\mathrm{Cl}=\mathrm{C2}$, the circuit will oscillate at a frequency equal to $1 /(2 \pi \mathrm{Rl} \mathrm{Cl}) \mathrm{Hz}$. 
Amplifier $A l$ is a conventional operational amplifier of sufficient bandwidth. Field effect transistor $Q 1$ operates as a voltage-controlled resistor and forms a voltage divider with R4. The AGC detector controls net gain through Q1 so as to maintain an output sinusoid of the desired amplitude.

In the bandpass filter mode, the circuit acts as a $Q$ multiplier to obtain Q's or sharpness merit factors of up to 200. Input and feedback resistors, $R_{i n}$ and $R_{f}$, are placed in the network and the AGC is replaced by an adjustable gain pot R3 and resistor R5. This potentiometer controls the $Q$ of the filter by adjusting the noninverting gain of the operational amplifier over a range of 2.8 to 3.0. The impedance of the tuning network as seen from the junction of $R_{\text {in }}-R_{f}$ should be at least 10 times the value of $R_{f}$, but should be at least 10 times less than the input impedance of the noninverting amplifier input. At the center frequency the amplifier and network provide an in-phase gain $A$ between the $R_{i n}-R_{f}$ junction and the output of nearly unity: For other frequencies the gain acquires a nonzero phase angle. The transfer function for the filter is:

$$
V_{\text {out }}=\frac{A V_{\text {in }}}{1+\frac{R_{\text {in }}}{R_{f}}(1-A)}
$$

At the center frequency the gain $A$ is $1 \angle^{\circ}$ and the expression reduces to $v_{\text {out }}=V_{\text {in }}$. The output drops away sharply as the input frequency deviates from the center frequency. A frequency response characteristic of the filter as set for a $Q$ of 200 and a center frequency of $25 \mathrm{kHz}$ is shown in Figure 11. The circuit is stable until the net gain is increased to a value equal to $\left(R_{f}+R_{i n}\right) / R_{i n}$, at which point oscillation will occur. For values shown in Figure 11 , the circuit is stable until the gain reaches a value of 1.005 .

Digital automatic nulling is accomplished by adding sine and cosine reference signals to the amplified coil signal so that the sum is zero. The reference signals are generated with multiplying digital to analog converters (DAC's). Constant amplitude sine and cosine waves at the test frequency form 
one input to the DAC's, and the other inputs are generated with digital counters. The DAC outputs are the product of these two values and can accommodate a wide range of signal amplitudes. Control electronics clock the counters up or down until the summed signal output is zero.

\section{CONCLUSIONS}

A specialized eddy current system has been developed and successfully implemented for process control of cartridge case manufacturing. The system has demonstrated the ability to successfully eject faulty cartridge cases which, if used, could result in jamming or misfire of weapons.

The system incorporates some unique design features which make it particulariy suited for special purpose high speed inspection applications. These features include advanced coil designs, and circuitry designed for production environment performance and simplicity of system operation. 


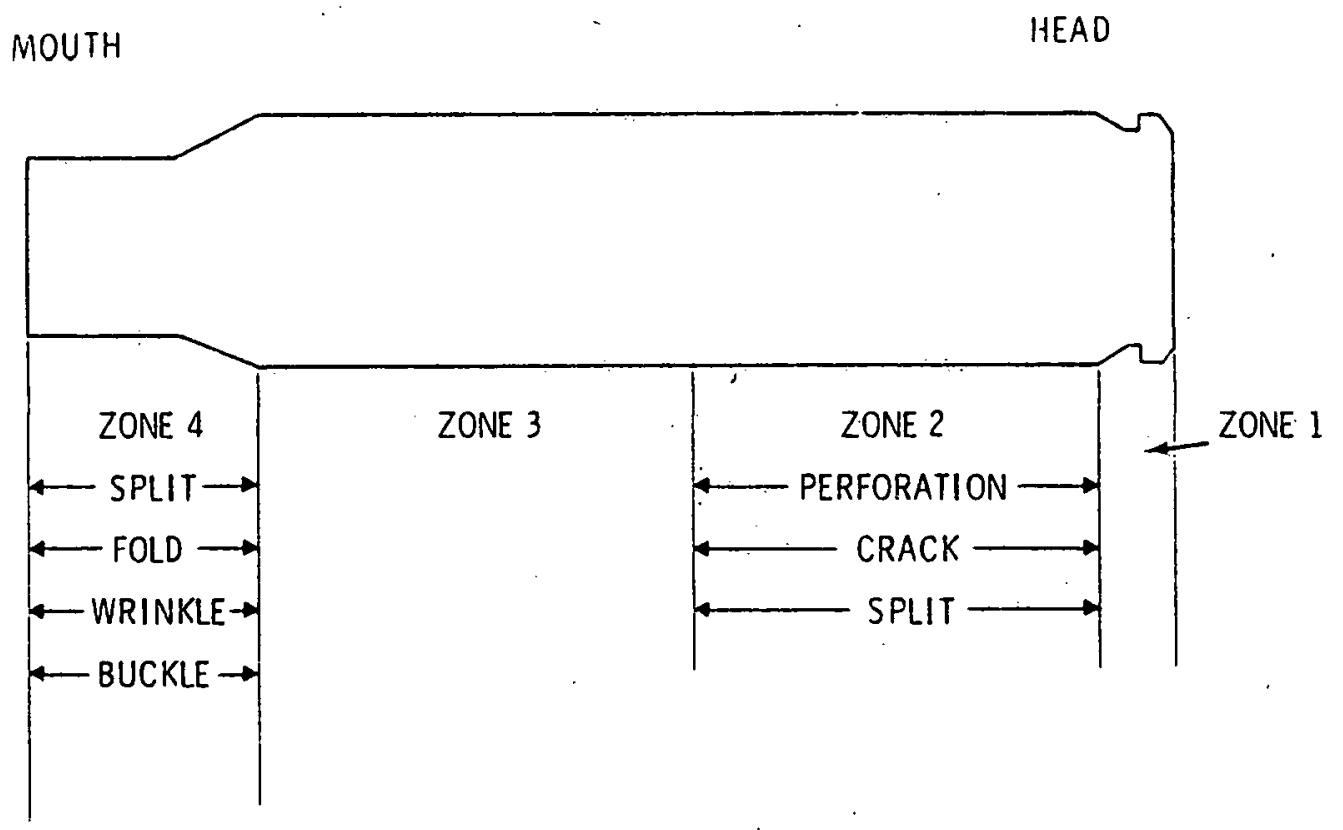

Figure 1. Defect inspection zones of cartridge case. (Zones 2 and 4 ) 


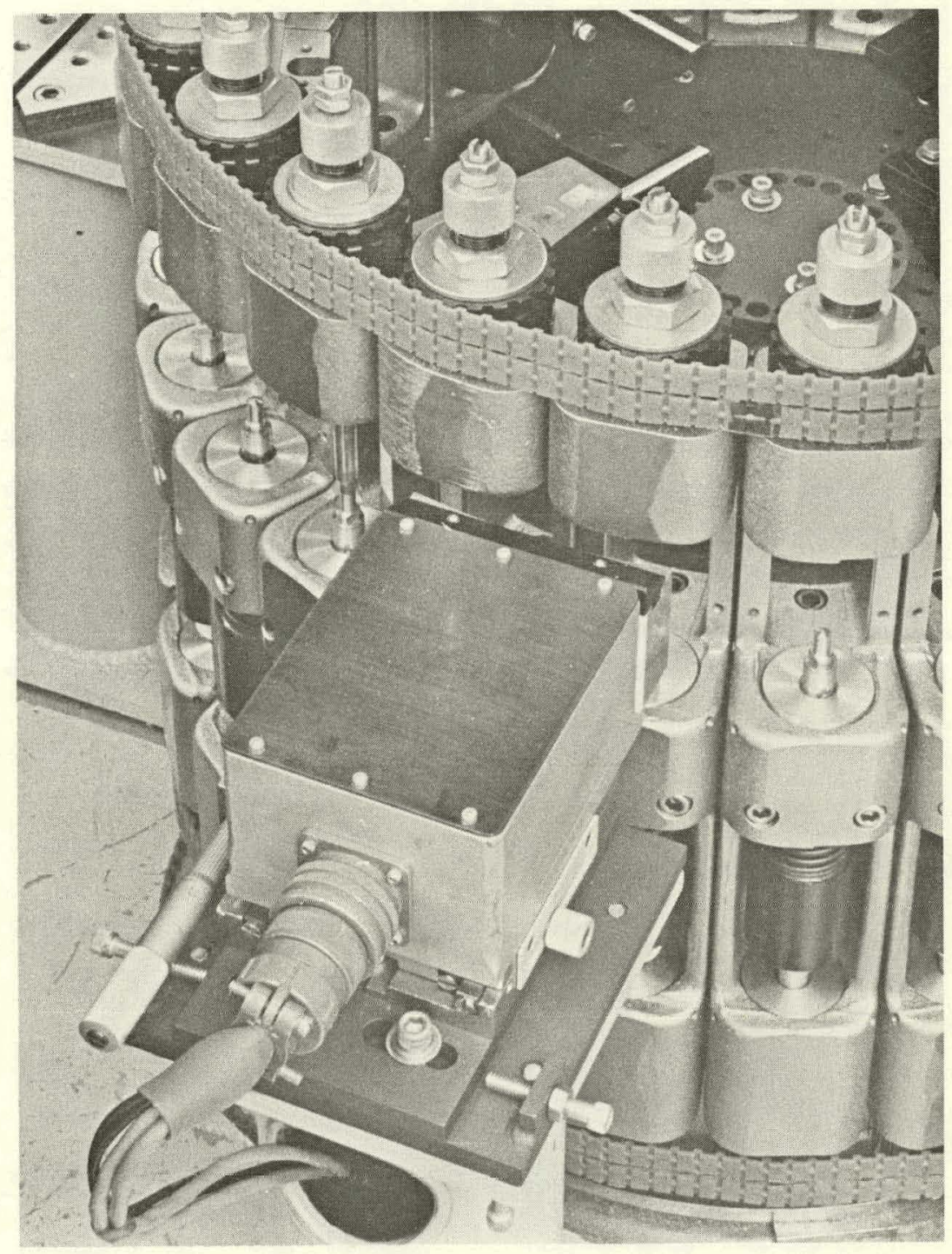

Figure 2. Eddy current probe assembly mounted on cartridge trasnport system. 


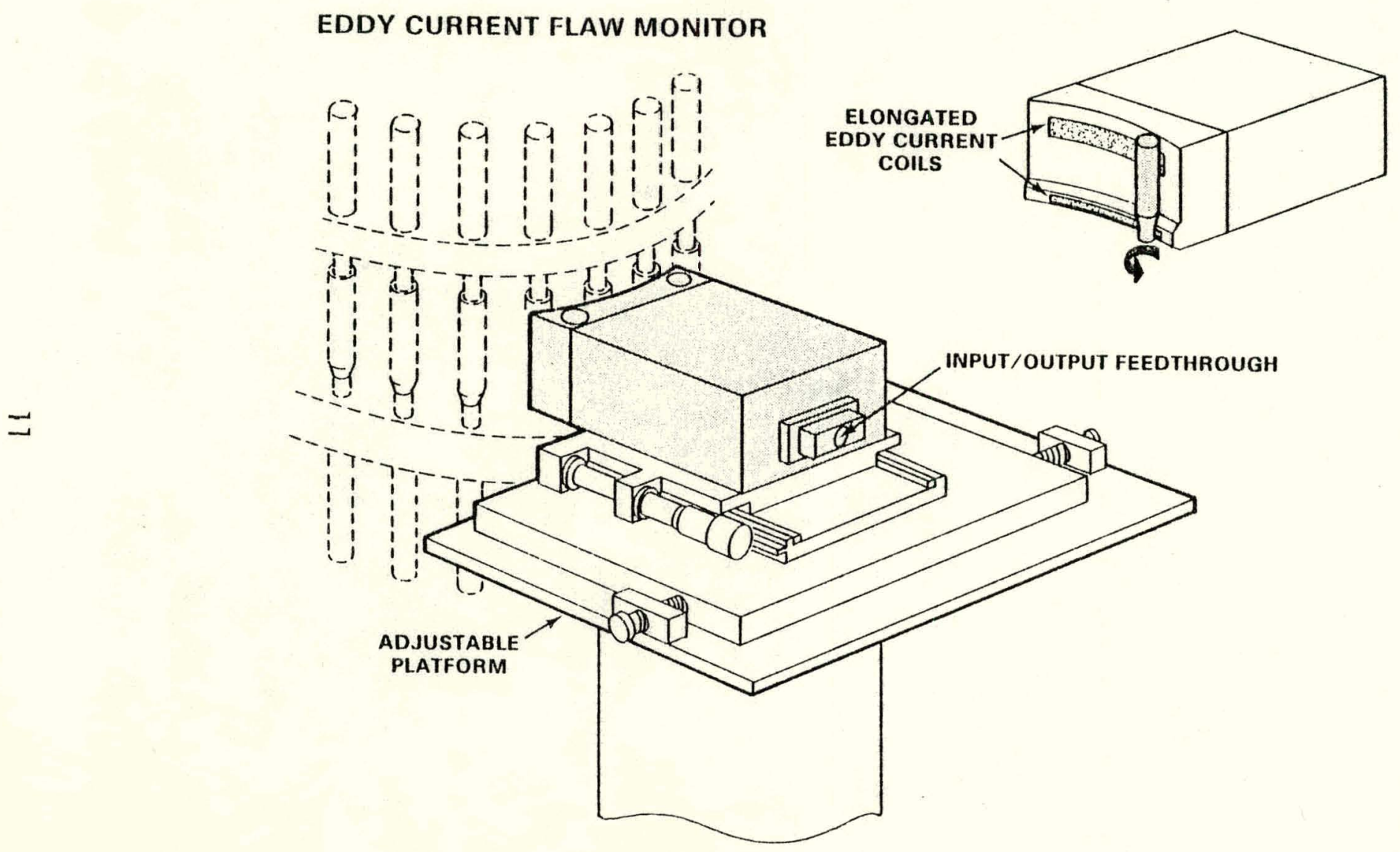

Figure 3. Mechanical details of translating a cartridge past the eddy current probe. 


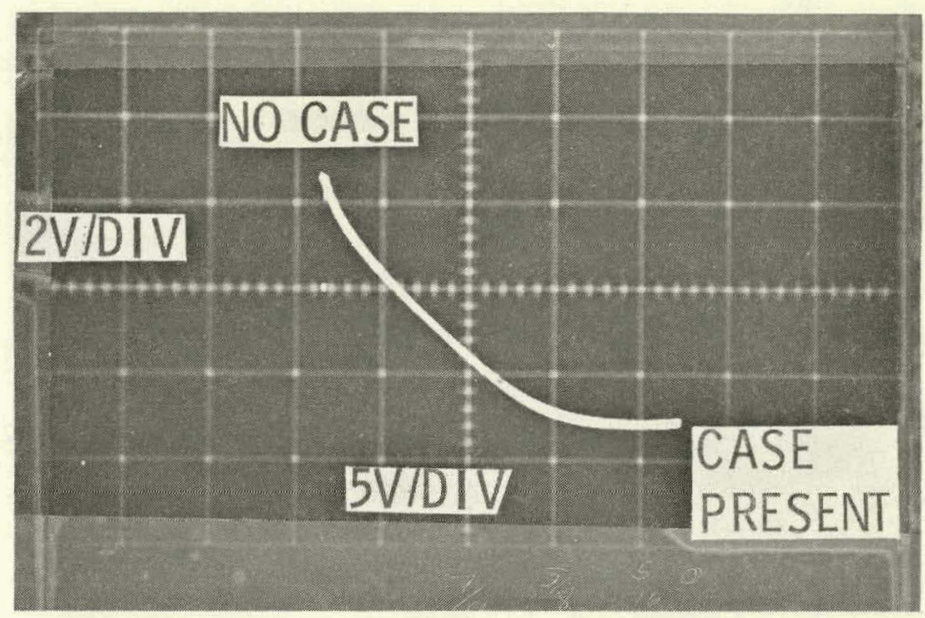

Figure 4-a. Complex impedance plane response as unflawed case is translated past eddy current probe.

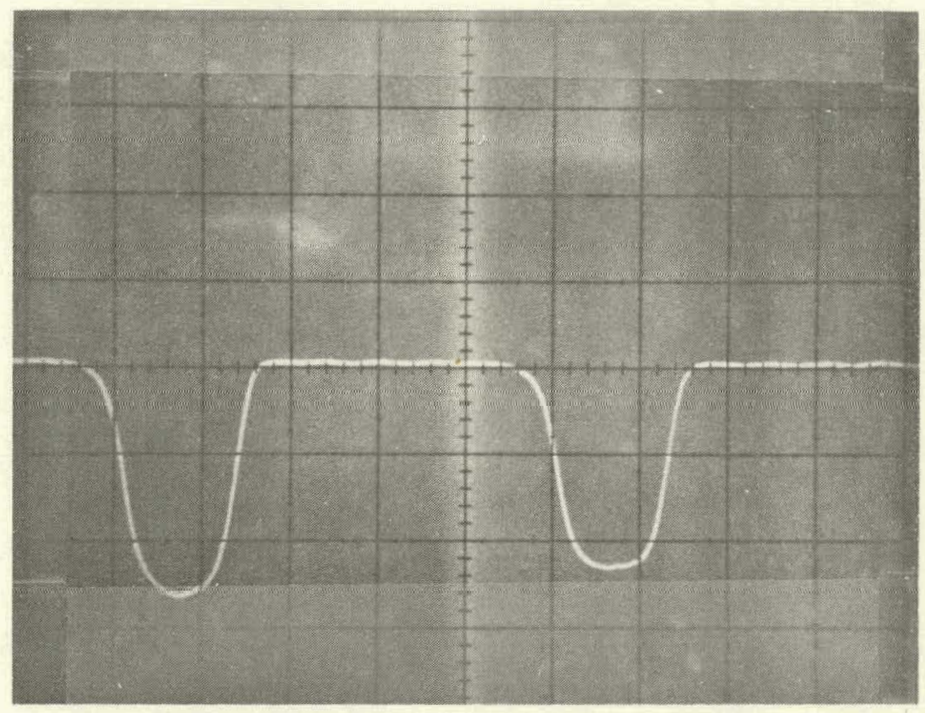

\section{Case $1 \quad$ Case 2}

Figure 4-b. Processed vertical channel of impedance plane response as two cases of different wall thicknesses are translated past the probe during a $25 \mathrm{kHz}$ test. Case 1 thickness is $0.495 \mathrm{~mm}(0.0195 \mathrm{in})$ and case 2 thickness is $0.48 \mathrm{~mm}(0.019 \mathrm{in})$. 


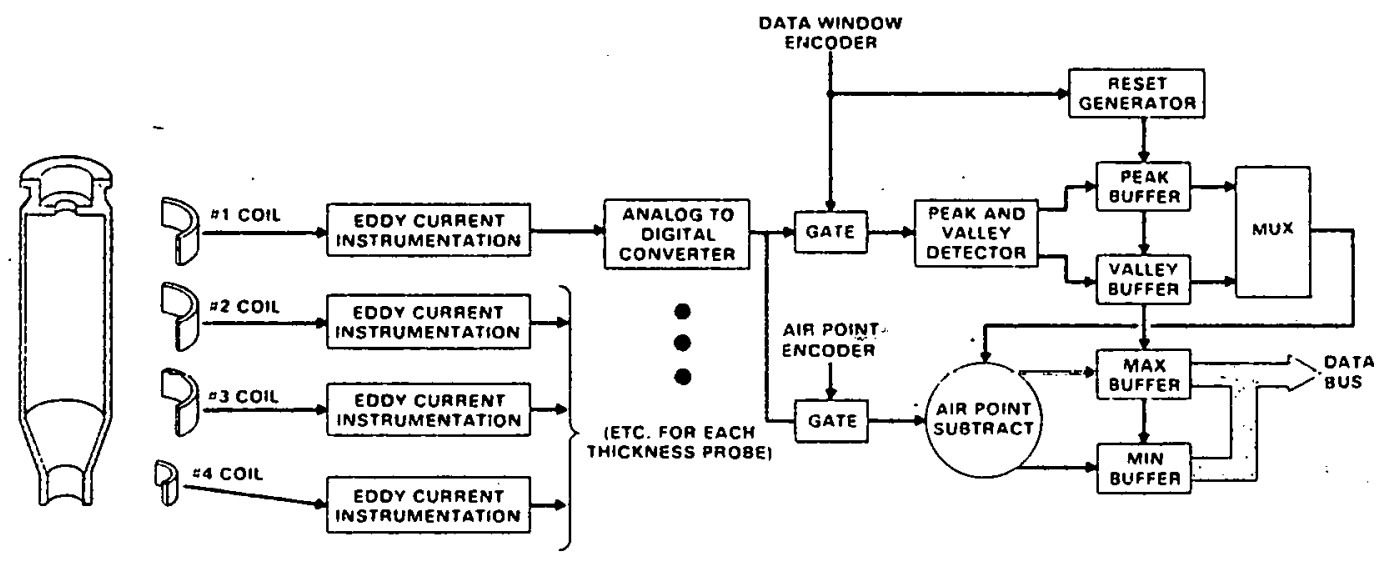

Figure 5. Basic block diagram of case thickness measurement instrumentation. 


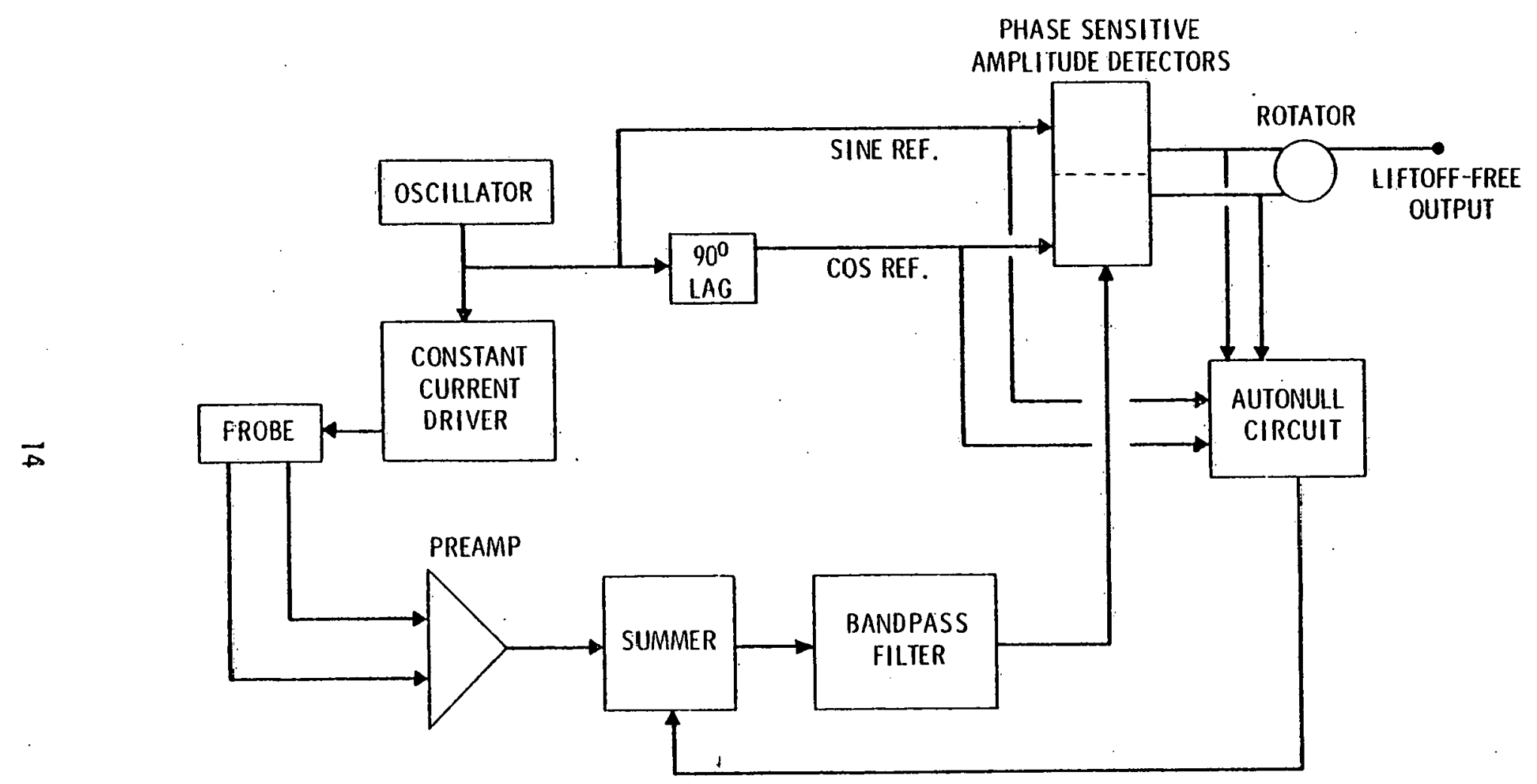

Figure 6. Block diagram of eddy current electronics. 


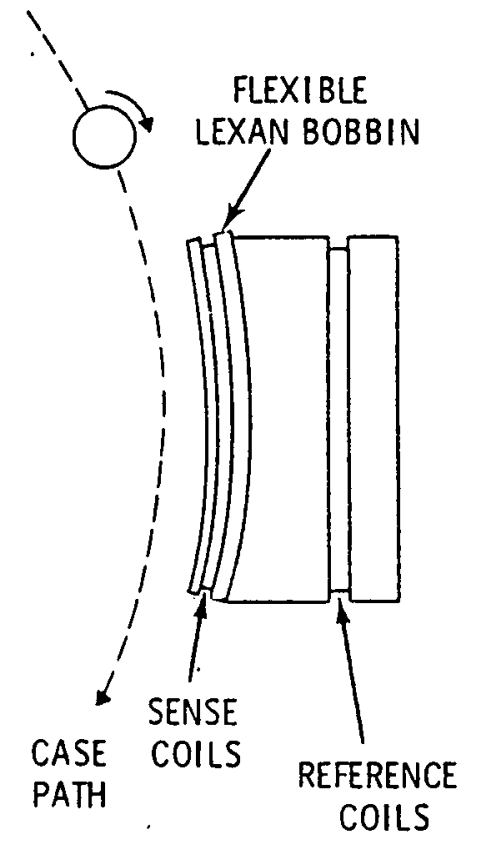

END VIEW

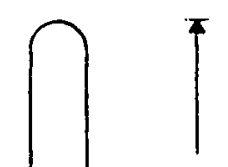

$41.4 \mathrm{~mm}$

Figure 7. Elongated coil form with circular contour.

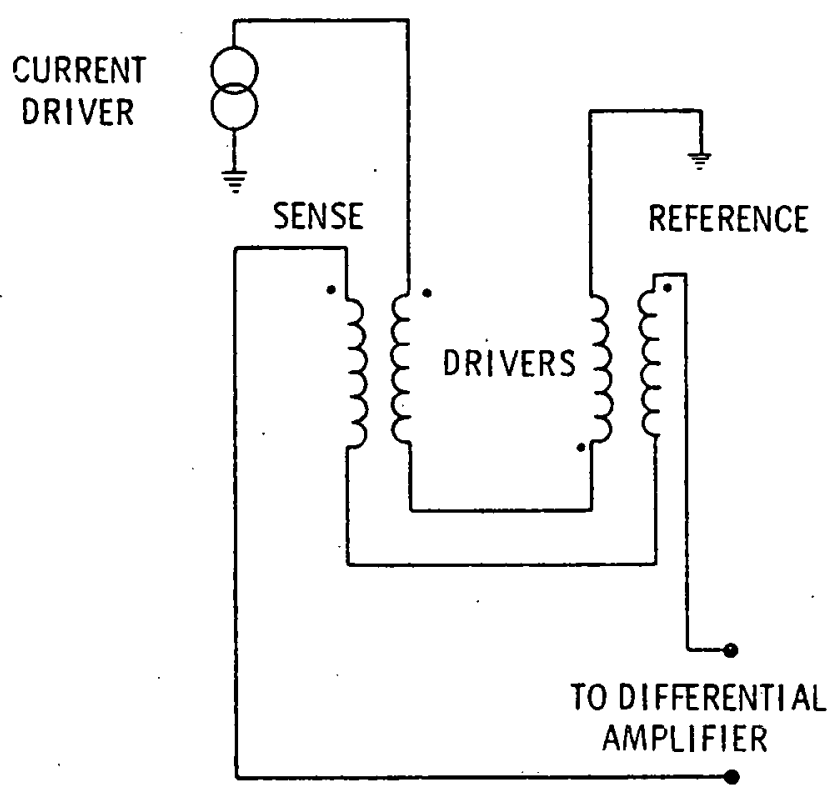

Figure 8. Electrical arrangement of coils. 


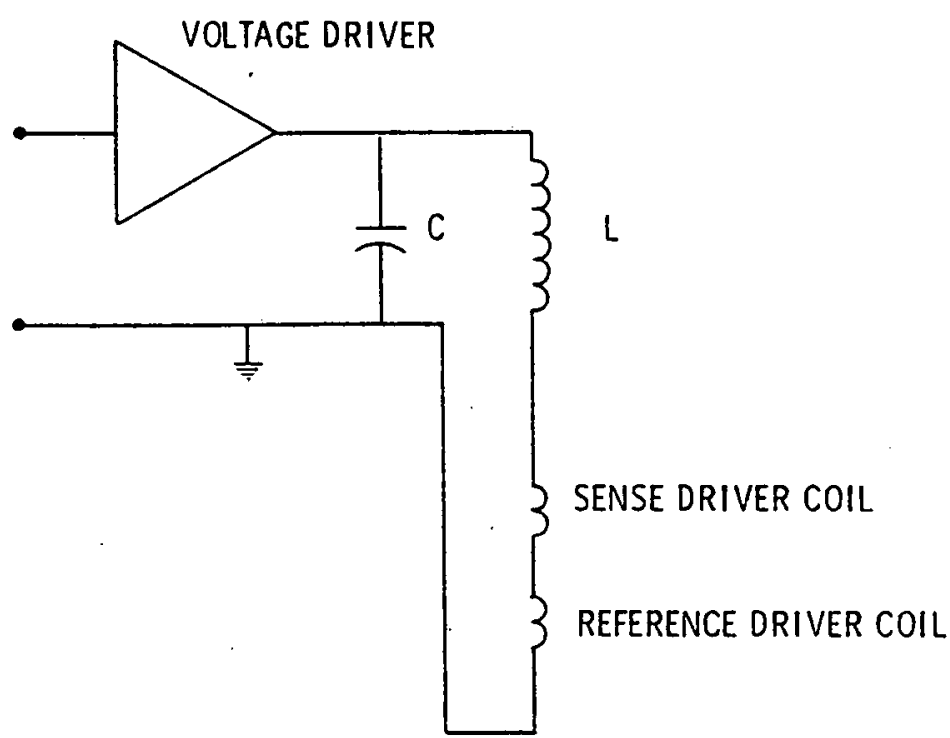

Figure 9. Constant current generator for coil excitation.

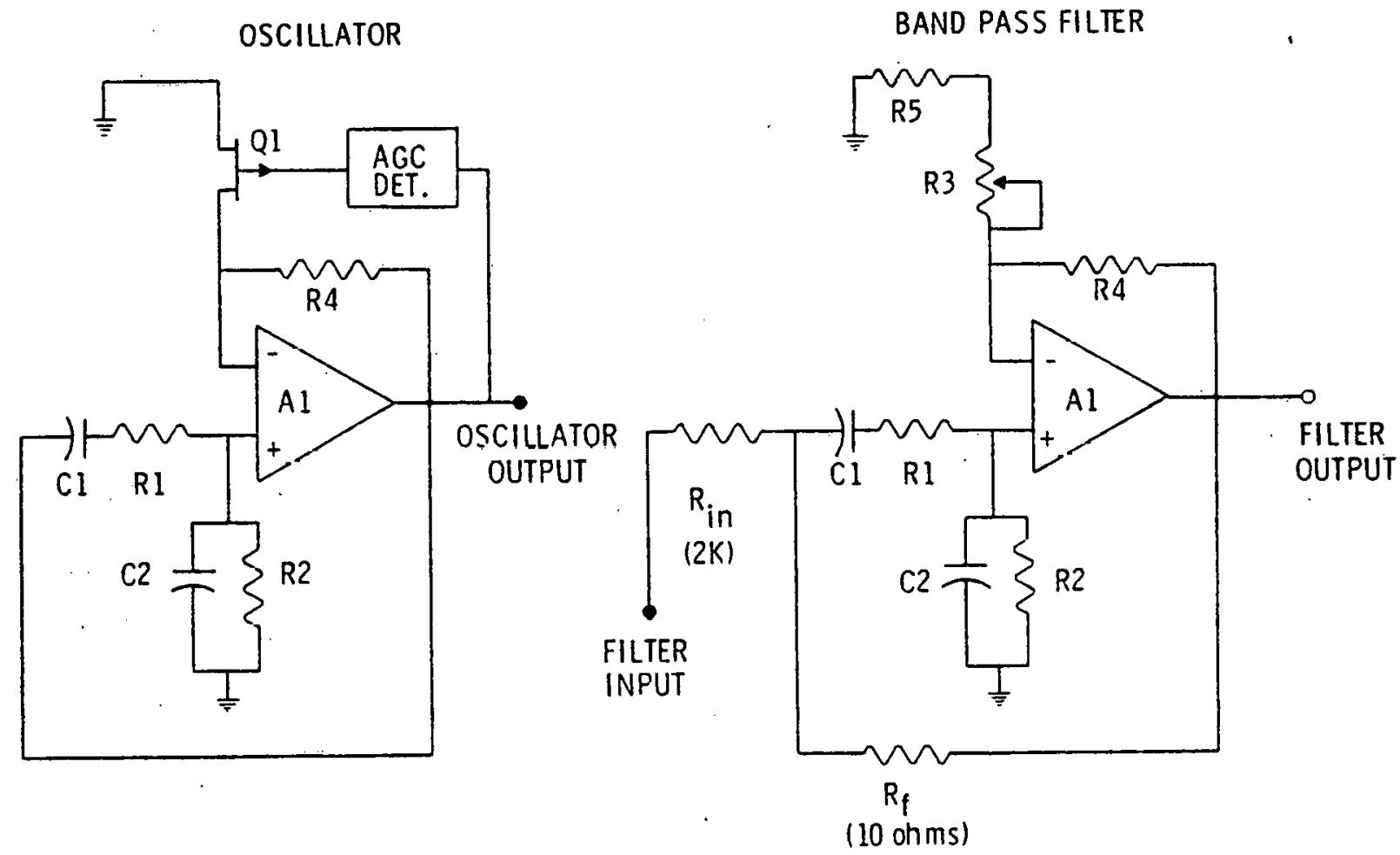

Figure 10. Oscillator and bandpass filtering circuits. 


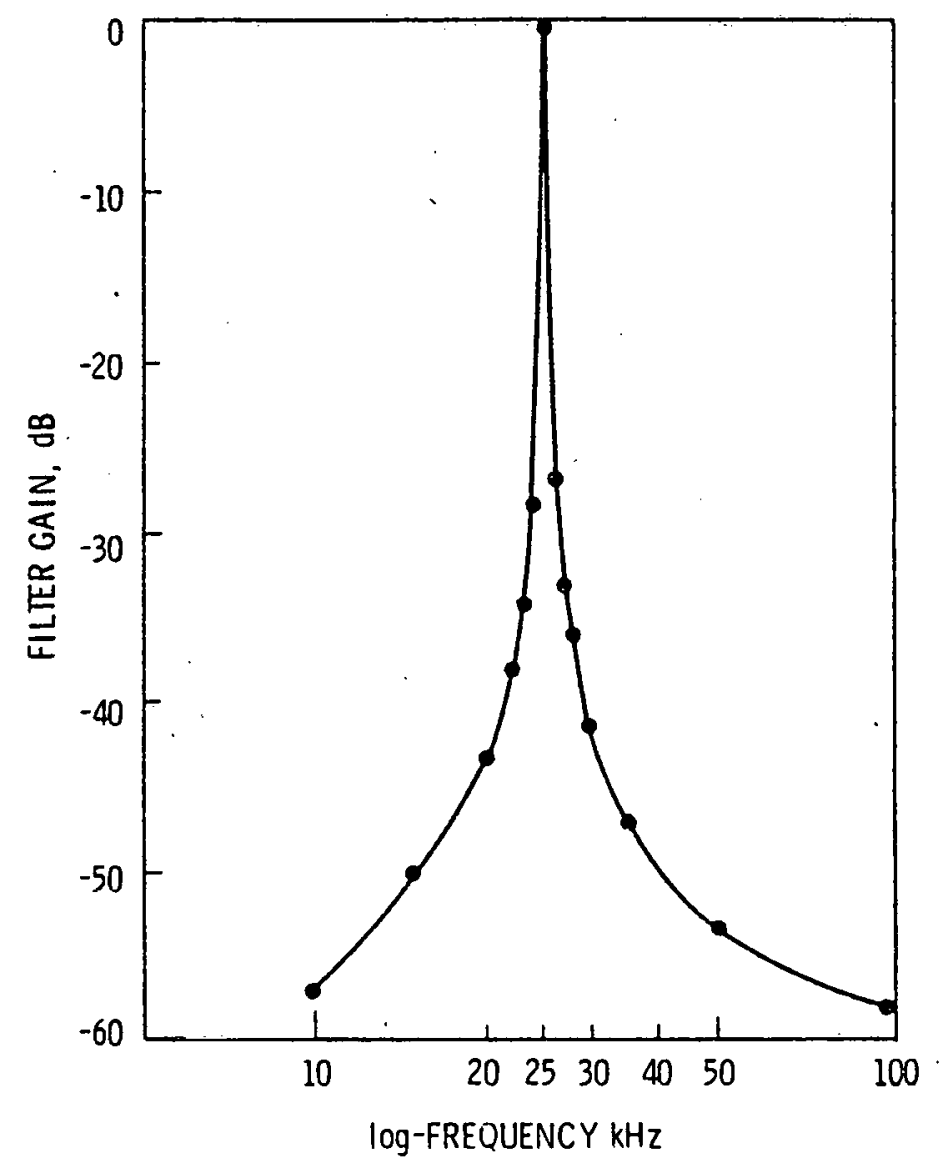

Figure 11. Frequency response of bandpass filter with a center frequency of $25 \mathrm{kHz}$. 